\title{
Prevalence of Allergic Rhinitis and Individual Prevention Practices Among Textile Workers in Vietnam
}

\author{
Thuc Thi Minh $\mathrm{Vu}^{1}$, Zaw Maung ${ }^{2}$, Long Giang Nguyen ${ }^{3}$, Hung Quang Nguyen ${ }^{4}$, Tung Thanh Truong ${ }^{5}$, Ky Minh \\ $\mathrm{Le}^{6}$, Trong Nguyen Tuan ${ }^{7}$, Binh Thanh $\mathrm{Ngo}^{8}$, Phuong Hoang Nguyen ${ }^{9}$, Tung Thanh $\operatorname{Tran}^{10^{*}}$, Cuong Tat Nguyen ${ }^{10}$, \\ Bach Xuan Tran ${ }^{2,11}$, Carl A. Latkin ${ }^{2}$, Cyrus SH Ho ${ }^{12}$ \& Roger CM Ho ${ }^{13}$ \\ ${ }^{1}$ Tam Anh Hospital, Hanoi, Vietnam \\ 2 Johns Hopkins University, Baltimore, Maryland, United States \\ ${ }^{3}$ Hai Phong University of Medicine and Pharmacy, Hai Phong, Vietnam \\ ${ }^{4}$ Otolaryngology Department, Viet Tiep Hospital, Hai Phong, Vietnam \\ ${ }^{5}$ Urology Department, Thanh Hoa Hospital, Thanh Hoa, Vietnam \\ ${ }^{6}$ Head and neck surgery center, National ENT Hospital, Hanoi, Vietnam \\ ${ }^{7}$ ENT Department, Vinh Medical University, Vinh, Vietnam \\ ${ }^{8}$ Otorhinolaryngology department, Thai Binh University of Medicine and Pharmacy, Thai Binh, Vietnam \\ ${ }^{9}$ Allergy and clinical immunology center, Bach Mai Hospital, Hanoi, Vietnam \\ ${ }^{10}$ Institute for Global Health Innovations, Duy Tan University, Da Nang, Vietnam \\ ${ }^{11}$ Institute for Preventive Medicine and Public Health, Hanoi Medical University, Hanoi, Vietnam \\ ${ }^{12}$ Department of Psychological Medicine, National University Hospital, Singapore \\ ${ }^{13}$ Department of Psychological Medicine, Yong Loo Lin School of Medicine, National University of Singapore, \\ Singapore \\ Correspondence: Tung Thanh Tran, Insitute for Globah Health Innovations, Duy Tan University, 73 Hoang Cau, \\ Dong Da, Hanoi 100000, Vietnam. Tel: 84-902-069-119. E-mail: tung.ighi@gmail.com
}

Received: May 2, 2018 Accepted: May 20, 2018 Online Published: June 1, 2018

doi:10.5539/gjhs.v10n7p43 URL: https://doi.org/10.5539/gjhs.v10n7p43

\begin{abstract}
The object of this study is to estimate the pervalence of rhinitis symptoms amongst textile workers and individual prevention practices currently used by workers in textile factories in Vietnam. A cross-sectional study was conducted in two textile garment companies in the Nam Dinh province of Vietnam from May to October 2016. A total of 1082 workers in all stages of the textile production process participated in the study. Itchy nose and sneeze were the most common symptoms (with $46.9 \%$ and $46.9 \%$, respectively, followed by itchy $(33.2 \%)$ and runny nose (24.5\%). Duration of cotton dust exposure per day were positively associated with face mask use $(\mathrm{OR}=1.90 ; 95 \%$ $\mathrm{CI}=1.24$ - 2.90) regular face mask use $(\mathrm{OR}=2.5 ; 95 \% \mathrm{CI}=1.87-3.33)$ and nasal spray before working $(\mathrm{OR}=4.2$; $95 \% \mathrm{CI}=1.49-11.83$ ). A high pervalence of allergic OR is observed amongst textile workers in Vietnam highlighting the need for preventive measures to reduce exposure to cotton dust.
\end{abstract}

Keywords: allergic, textile workers, Vietnam

\section{Introduction}

The nasal passageway and the respiratory tract is a main point of entry for foreign substances into the body. The nasal fossa is often the first point of contact to inhaled agents including gases, vapors, and aerosols (Dantas, Valera, Zappelini, \& Anselmo-Lima, 2013). Exposure to an array of irritants and allergens in the environment can therefore elicit an inflammatory response. When the nasal mucosa is exposed to a noxious stimuli, it can respond with vasodilation, increased vascular permeability, nervous sensory stimulation, and gland stimulation causing symptoms of rhinitis including nasal congestion, itching, sneezing, and rhinorrhea (Moscato et al., 2008). In addition to irritants and allergens, rhinitis can be also be caused by viruses and bacteria (Moscato et al., 2008).

When rhinitis occurs as the result of exposure to an external stimuli encountered in the workplace, it is called 
occupational rhinitis. ${ }^{3}$ This is differentiated from pre-existing rhinitis that may be exacerabated at work or with concomitant rhinitis (allergic and non-allergic) that may worsen at work (Sublett \& Bernstein, 2011). Occupational rhinitis can occur in a number of different work settings. Occupational rhinitis is further classified into Allergic or Non-allergic based on the underlying disease mechanism (Moscato et al., 2008). Non-allergic refers to the non-immunologic response following a single high-level exposure to a chemical irritant or combustion product and is often referred to as irritant-induced rhinitis or Reactive Upper Airways Dysfunction Syndrome(Sublett \& Bernstein, 2011). Allergic on the other hand is an immune-mediated hypersensitivity reaction to a particular agent and is clasically characterized by a period of latency (Stevens \& Grammer, 2015). The underlying mechanism mediating immunologic resonse in allergic is the development of specific $\operatorname{IgE}$ antibodies after exposure to the causative agent. On re-exposure to the sensitized agent, there is a TH2 mediated immune response. However, not all allergic is mediated by IgE, as some of the immune response to the causative agents can also be mediated by IgG antibodies or other components of the adaptive immune response. The causative agents of allergic are categorized into high moelcular weight allergens or low molecular weight allergens. HMW and LMW allergens can bind to proteins and elicit allergic response. Known examples of substances known to cause allergic include rodent allergens in laboratory workers and latex in health care workers.

Workers in the textile industry are at increased risk of developing occupational rhinitis and spectrum of other respiratory disorders from exposure to cotton dust, raw materials, and by-products of several chemicals used (Christiani et al., 1996; Nagoda, Okpapi, Babashani, M, \& J.U, 2012). Much of the current understanding on health hazards amongst textile workers comes from research in China(Christiani et al., 1996), Europe (Schilling, Hughes, Dingwall-Fordyce, \& Gilson, 1955), and America (Dubrow \& Gute, 1988; Zuskin et al., 1998). There is paucity of literature on occupational rhinitis amongst textile workers in Vietnam. Vietnam has a growing textile industry with more than 3800 companies and ranks fifth in the world in textile and apparel exports (ITA, 2016). The textile industry in Vietnam has a laborforce of more than 2 million people with an estimated 1.3 million working directly in the industry(ITA, 2016). Thus, there is a need to understand the prevalence of rhinitis and other respiratory conditions as well as relevant health hazards in this industry to strengthen the existing system to protect workers' health and increase safety practices. The object of this study is to estimate the pervalence of rhinitis symptoms amongst textile workers and prevention practices currently used in textile factories in Vietnam.

\section{Method}

\subsection{Study Design}

A cross-sectional study was conducted in the Nam Dinh province of Vietnam from May to October 2016. Two textile garment companies (Nam Dinh and Song Hong) were selected to recruit participants. Participants were considered to be directly exposed to cotton dust when working in these factories. Other exposures were not measured in this study. We included all workers of these two companies if they met following criteria: 1) directly participated in the production process; 2) Volunteered to participate in the study; 3) agree to give informed consent; and 4) Having no history of allergic rhinitis before working in the factories. Workers in all stages of the production process including harvesting, preparatory processes, spinning, weaving, and finishing were included. A total of 1082 workers were invited to participate in this study

\subsection{Data Collection and Measurements}

In this study, we combined both clinical examination, laboratory tests and interview with structured questionnaire to collect the data. Clinical examination included: weight, height, ENT, Odonto-stomatology, general physical exam and obstetrics.

Data collectors were medical doctors with experiences in occupational health and respiratory diseases. Before doing data collection, these medical doctors were underwent an intensive training in order to ensure the quality and consistency of data.

We collected data about socio-demographic characteristics (gender, age) and labor experience (years of experience, degree of competencies). We also examined the time of cotton dust exposure per day and whether the workers suffered from allergic rhinitis or not. Participants self-assessed how many hours they were exposured to cotton dust per day. Participants were diagnosed with allergic rhinitis based on laboratory tests in tandem with other symptoms such as sneezing, nasal congestion, nasal itching, rhinorrhea, anosmia and headache.

Practices to prevent allergic rhinitis among workers included the use of face mask, frequency of using face mask, type of face mask and nasal spray before working. Participants were asked whether they use nasal spray to prevent allergic rhinitis. The textile companies only offered masks to the workers. 


\subsection{Statistic Analysis}

STATA software version 12.0 was used to analyze the data. P-value $<0.05$ was considered statistical significance. In this study, we used Chi-squared to examine the difference of allergic rhinitis prevention practices between male and female. Logistic regression was employed to identify the factors associated with the prevention practices (such as wearing mask and using nasal spray). In this study, a stepwise backward selection strategy was applied along with multivariate Logistic regression to have reduced models. This strategy used threshold with the log-likelihood ratio test to have predictors with $\mathrm{p}$-values of $<0.2$ included.

\subsection{Ethical Approval}

This study's protocol was approved by the IRB of .... Data collection procedures were also approved by the directors of the two companies. Written informed consent was obtained from all participants.

\section{Results}

Table 1. Demographic and allergic rhinitis characteristics among workers

\begin{tabular}{|c|c|c|c|c|c|c|c|}
\hline \multirow{2}{*}{ Characteristics } & \multicolumn{2}{|c|}{ Male } & \multicolumn{2}{|c|}{ Female } & \multicolumn{2}{|l|}{ Total } & \multirow[t]{2}{*}{ p-value } \\
\hline & $\mathbf{n}$ & $\%$ & n & $\%$ & $\mathbf{n}$ & $\%$ & \\
\hline Total & 334 & 30.9 & 748 & 69.1 & 1,082 & 100 & \\
\hline \multicolumn{8}{|l|}{ Age group } \\
\hline $20-29$ & 103 & 29.9 & 118 & 15.8 & 221 & 20.4 & \multirow[t]{5}{*}{$<0.01$} \\
\hline $30-39$ & 139 & 40.4 & 394 & 52.7 & 533 & 49.3 & \\
\hline $40-49$ & 47 & 13.7 & 168 & 22.5 & 215 & 19.9 & \\
\hline $50-59$ & 41 & 11.9 & 65 & 8.7 & 106 & 9.8 & \\
\hline$>=60$ & 4 & 1.2 & 3 & 0.4 & 7 & 0.6 & \\
\hline \multicolumn{8}{|c|}{ Years of experience } \\
\hline$<5$ years & 112 & 32.6 & 130 & 17.4 & 242 & 22.4 & \multirow[t]{3}{*}{$<0.01$} \\
\hline $5-10$ years & 104 & 30.2 & 189 & 25.4 & 293 & 27.2 & \\
\hline$>10$ years & 118 & 34.3 & 426 & 57.2 & 544 & 50.4 & \\
\hline \multicolumn{8}{|c|}{ Time of cotton dust exposure per day } \\
\hline No & 31 & 10.5 & 92 & 14.2 & 123 & 13.1 & \multirow[t]{4}{*}{0.09} \\
\hline $1-4$ hours & 20 & 6.8 & 25 & 3.9 & 45 & 4.8 & \\
\hline $4-8$ hours & 174 & 59.2 & 363 & 56.1 & 537 & 57.1 & \\
\hline $9-11$ hours & 69 & 23.5 & 167 & 25.8 & 236 & 25.1 & \\
\hline \multicolumn{8}{|l|}{ Allergic Rhinitis } \\
\hline No & 146 & 44.0 & 363 & 49.0 & 509 & 47.4 & \multirow[t]{2}{*}{0.13} \\
\hline Yes & 186 & 56.0 & 378 & 51.0 & 564 & 52.6 & \\
\hline
\end{tabular}

Table 1 shows that most of the participants were female (69.1\%), from 20 to 39 years old (69.7\%), having more than ten years of working experience (50.4\%), exposing cotton dust 4-8 hours/day. More than a half of the participants met the criteria for diagnosis of allergic rhinitis $(52.6 \%)$. 


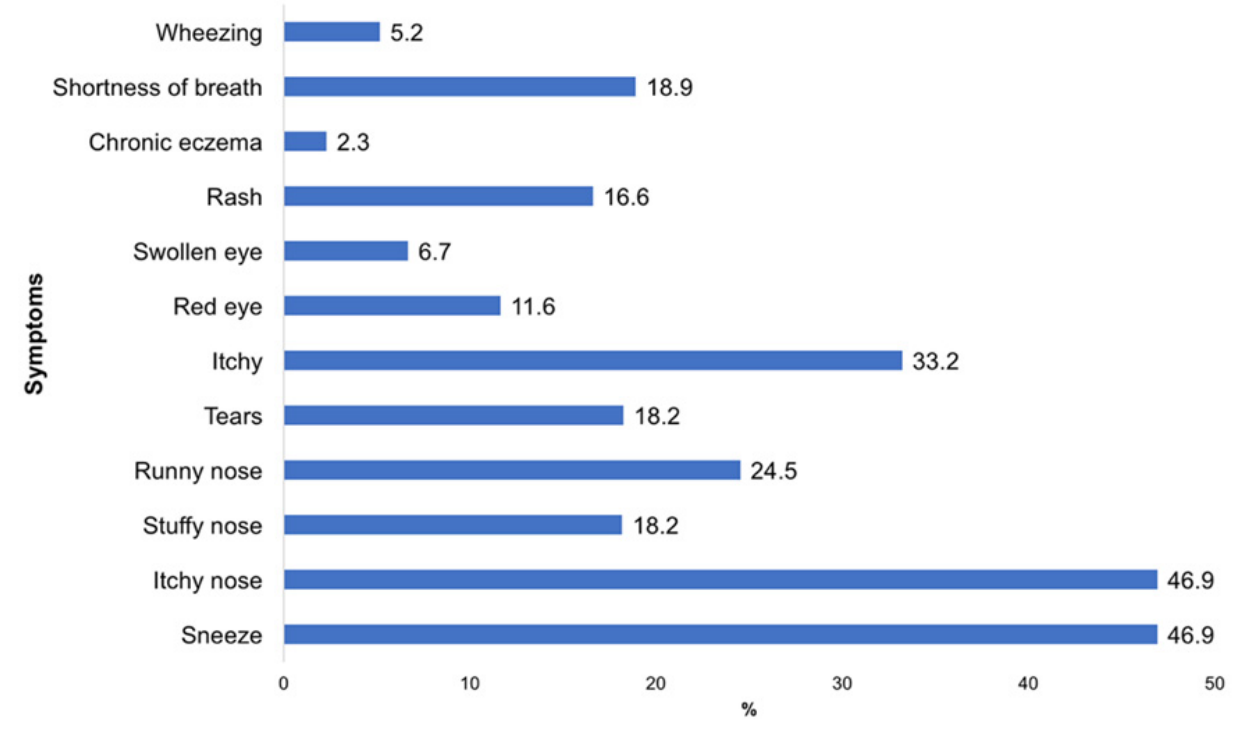

Figure 1. Prevalence of symptoms among participants

Figure 1 shows that itchy nose and sneeze were the most dominant symptoms (with $46.9 \%$ and $46.9 \%$, respectively, followed by itchy $(33.2 \%)$ and runny nose $(24.5 \%)$.

Table 2. Allergic rhinitis prevention practice

\begin{tabular}{|c|c|c|c|c|c|c|c|}
\hline \multirow{2}{*}{ Characteristics } & \multicolumn{2}{|c|}{ Male } & \multicolumn{2}{|c|}{ Female } & \multicolumn{2}{|c|}{ Total } & \multirow{2}{*}{ p-value } \\
\hline & n & $\%$ & n & $\%$ & $\mathbf{n}$ & $\%$ & \\
\hline \multicolumn{8}{|l|}{ Used face mask } \\
\hline No & 40 & 12.2 & 75 & 10.4 & 115 & 11.0 & 0.38 \\
\hline Yes & 287 & 87.8 & 646 & 89.6 & 933 & 89.0 & \\
\hline \multicolumn{8}{|c|}{ Regularly used face mask } \\
\hline No & 108 & 34.3 & 229 & 33.0 & 337 & 33.4 & 0.69 \\
\hline Yes & 207 & 65.7 & 465 & 67.0 & 672 & 66.6 & \\
\hline \multicolumn{8}{|l|}{ Type of face mask } \\
\hline Common-face-mask & 261 & 88.2 & 561 & 83.9 & 822 & 85.2 & 0.08 \\
\hline Professional face mask & 35 & 11.8 & 108 & 16.1 & 143 & 14.8 & \\
\hline \multicolumn{8}{|c|}{ Nasal spray before working } \\
\hline No & 306 & 94.4 & 656 & 91.8 & 962 & 92.6 & 0.12 \\
\hline Yes & 18 & 5.6 & 59 & 8.3 & 77 & 7.4 & \\
\hline
\end{tabular}

Table 2 shows that most of the participants used face mask (89.0\%), used common-face-mask $(85.2 \%)$ and had no nasal spray before labor $(92.6 \%)$. No differences of prevention practice were found between male and female. 
Table 3. Associated factors related to personal preventive practices of allergic rhinitis

\begin{tabular}{|c|c|c|c|c|c|c|}
\hline \multirow[t]{2}{*}{ Characteristics } & \multicolumn{2}{|c|}{ Use face mask } & \multicolumn{2}{|c|}{$\begin{array}{l}\text { Regularly use face } \\
\text { mask }\end{array}$} & \multicolumn{2}{|c|}{$\begin{array}{l}\text { Nasal spray before } \\
\text { working }\end{array}$} \\
\hline & OR & $95 \% \mathrm{CI}$ & OR & $95 \% \mathrm{CI}$ & $\overline{\text { OR }}$ & $95 \% \mathrm{CI}$ \\
\hline \multicolumn{7}{|c|}{ Time of cotton dust exposure per } \\
\hline \multicolumn{7}{|l|}{$\left({ }^{\mathrm{a}} \mathrm{No}\right)$} \\
\hline $4-8$ hours & $1.90^{* * *}$ & $(1.24-2.90)$ & $2.50^{* * *}$ & $(1.87-3.33)$ & $4.20^{* * *}$ & $(1.49-11.83)$ \\
\hline $9-11$ hours & & & & & $3.01 *$ & $(0.99-9.14)$ \\
\hline \multicolumn{7}{|l|}{ Gender } \\
\hline ( ${ }^{\mathrm{a}}$ Male) & Ref & & Ref & & & \\
\hline Female & & & 1.23 & $(0.91-1.68)$ & & \\
\hline \multicolumn{7}{|c|}{ Years of experience } \\
\hline$\left({ }^{a}<5\right.$ years $)$ & Ref & & & & & \\
\hline $5-10$ years & & & & & $4.07 * * *$ & $(1.70-9.75)$ \\
\hline$>10$ years & & & & & $2.62 * *$ & $(1.15-5.99)$ \\
\hline \multicolumn{7}{|l|}{ Age groups } \\
\hline$\left({ }^{\text {a } 20-29)}\right.$ & Ref & & Ref & & Ref & \\
\hline $30-39$ & $1.95^{* * *}$ & $(1.26-3.01)$ & & & 0.70 & $(0.42-1.16)$ \\
\hline $50-59$ & & & $1.69^{*}$ & $(0.93-3.07)$ & & \\
\hline
\end{tabular}

Table 3 shows that duration of cotton dust exposure per day were positively associated with face mask use, regular face mask use and nasal spray before working. People with higher years of experience were more likely to take nasal spray before working. Meanwhile, people in age group 30-39 were more likely to use face mask compared to the younger group.

\section{Discussion}

The true pervalence of occupational rhinitis is difficult to determine due to variability in work environments across different sectors and lack of a uniform standard for diagnosis (Stevens \& Grammer, 2015). However, there are well-established industries and specific occupations that are at increased risk of developing OR. Workers in textile factories are exposed to cotton dust and other raw materials that are known to be allergens. Allergic OR causes symptomatic discomfort, negatively impacts quality of life and can lead to sinuonasal complications. It is a debilitating condition in the workplace and is associated with performance deficits, reduced productivity, and psychosocial problems.

This is the first study to our knowledge to look at the pervalence of allergic rhinitis and preventive practices used amongst textile workers in Vietnam. As shown in this study, the pervalence of allergic OR was $52.6 \%$. The most common symptoms were sneezing and itchy nose with $46.9 \%$ of particpants reporting symptoms, followed by itchy $(33.2 \%)$, runny nose $(24.5 \%)$, shortness of breath $(18.9 \%)$, tears $(18.2 \%)$, stuffy nose $(18.2 \%)$, red eyes $(11.6 \%)$, swollen eyes $(6.7 \%)$, and wheezing (5.2\%), respectively. The etiology of these symptoms experienced may be from exposure to cotton dust. There is also a positive association between the duration of exposure and use of personal protectiive equipment such as face mask and nasal spray prior to work. This suggests that workers are experiencing symptomatic discomfort with prolonged period of work and needing to use personal protection available to them. Furthermore, those with higher years of experience working in the textile factories were more likely to use nasal spray prior to work.

The results from this study is congruent with findings from studies amongst textile workers in other countries. Dantas et al. reported similar pervalence of rhinitis symptoms in textile industry workers in Sao Paulo, Brazil (Dantas et al., 2013). Similarly, Nagoda et al reported pervalence of $63 \%$ for respiratory symptoms and 59\% rhinitis amongst workers exposed to cotton dust in a textile company in Nigeria (Nagoda et al., 2012). Chaari et al. 
reported a lower pervalence of rhinitis symptoms (8.5\%) amongst 600 apprentice textile workers at a clothing vocational training centre in Monastir area of Tunisia (Chaari et al., 2009). The differences seen in prevalence rates may be attributable to differences in study methodology as well as differences in occupational safety and health practices implemented in these factories.

In the U.S., accounting for all types of employments, the pervalence of OR is estimated to be $7.5 \%$ (Stevens \& Grammer, 2015). However, the pervalence of OR is much higher in certain occupations. The highest pervalence rates of OR have been reported in laboratory animal handlers (estimated pervalence range from 10 to $42 \%$ ) and bakers in Norway (estimated to be between 23 and 50\%). When compared to these professions, workers in this study had a higher pervalence rate at $52 \%$. However, it is also important to note, much of variability is also attributable to lack of a uniform standard for diagnosis. Nonetheless, this study highlights the burden of rhinitis symptoms in textile workers in Vietnam; these findings are in line with reported literature on textile workers in other countries.

The primary method of treatment for occupational rhinitis is eliminating or reducing exposure to the causative agent. Given the high prevalence of allergic rhinitis in this study, it is necessary to implement preventive measures that aim to reduce exposure and prevent the disease from developing. In textile workers, there are different strategies of limiting exposure to cotton dust. This includes developing engineering interventions to improve ventilation, instituting administrative changes including limiting the number of hours of exposed, relocating to lower exposure areas, and wearing personal protective clothing and masks. Priorities, however, should be placed on engineering solutions to limit the exposure and thereby preventing the disease from developing. When avoidance to the causative agent (cotton dust) is not feasible, the use of personal protective equipments offers workers some type of protection. This study showed that although $89 \%$ of participant reported using face masks, only $66.6 \%$ used it routinely. Workers with higher years of experience were more likely to use pharmacological therapy (nasal spray) prior to work and people in age-group 30-39 were more likely to use face masks when compared to the younger cohort. This highlights the need to ensure routine and appropriate use of PPE, particularly for younger workers and new employees. Additionally, training should be provided about hazards in the textile factories and associated diseases, as well ensuring the appropriate and effective use of PPE.

Secondary prevention efforts to prevent the progression of symptoms in those sensitized individuals should also be implemented. This is particularly important to prevent the subsequent development of other respiratory disorders including occupational asthma. There is strong association between occupational rhinitis and occupational asthma. This include medical monitoring, surveillance, and early referral for treatment and if necessary removal or relocation to a different work environment. Environmental monitoring of exposure is necessary to guide control measusures.

\subsection{Limitations}

A limitation of this study is symptomatology of rhinitis may be underestimated due to the healthy worker effect. This is often a source of bias because sicker individuals often select to work in environments in which exposures are low or are precluded from being hired due to their sensitivity. Similarly, those hired may also quit their job or transfer to other facilities where their exposures are low. Additionally, since this is a self-administered questionaire, workers may be hesitant to report symptoms due to fear of losing their job or reprimandation.

\section{Conclusion}

This study showed a particularly high prevalence of allergic rhinitis amongst textile workers in Vietnam, underlining the need to develop prevention and treatment interventions to reduce symptomatic discomfort for workers in the textile industry. In addition to the use of indiviudal protective equipment such as face masks and pharmacological treatment with nasal sprays, engineering controls and administrative measures are necessary to minimize workers' exposure and improve working conditions. There are multiple socioeconomic implications from occupational rhinitis; symptomatic discomfort from OR decreases quality of life and reduces productivity. The progression of allergic rhinitis to other debilitating chronic conditions such as asthma can also lead to disability, increased healthcare costs, and lost of labor force. In Vietnam, the textile industry is a significant contributor to the growing economy and it is thus important to ensure the health and safety of the workers in this industry.

\section{Acknowledgments}

The authors would like to acknowledge the participants for their enrollment. 


\section{Data Availability}

Data can be retrieved by contacting the coresponding author.

\section{Funding Statement}

The authors declared that no grants were involved in supporting this work.

\section{Competing Interests Statement}

No competing interests were disclosed.

\section{References}

Chaari, N., Amri, C., Khalfallah, T., Alaya, A., Abdallah, B., Harzallah, L., .. \& Akrout, M. (2009). [Rhinitis and asthma related to cotton dust exposure in apprentices in the clothing industry]. Rev Mal Respir, 26(1), 29-36. https://doi.org/10.1016/S0761-8425(09)70131-7

Christiani, D. C., Wang, X.-r., Pan, L.-d., Zhang, H.-x., Sun, B.-x., Dai, H., ... \& Olenchock, S. A. (1996). Longitudinal Changes in Pulmonary Function and Respiratory Symptoms in Cotton Textile Workers. American Journal of Respiratory and Critical Care Medicine. https://doi.org/10.1164/ajrccm.163.4.2006063

Dantas, I. d. P., Valera, F. C. P., Zappelini, C. E. M., \& Anselmo-Lima, W. T. (2013). Prevalence of rhinitis symptoms among textile industry workers exposed to cotton dust. International Archives of Otorhinolaryngology, 17(1), 26-30. https://doi.org/10.7162/S1809-97772013000100005

Dubrow, R., \& Gute, D. M. (1988). Cause - specific mortality among male textile workers in Rhode Island. American Journal of Industrial Medicine, 13(4), 439-454. https://doi.org/10.1002/ajim.4700130404

ITA. (2016). 2016 Top Markets Report Technical Textiles Country Case Study Vietnam (pp. 1-3).

Moscato, G., Vandenplas, O., Van Wijk, R. G., Malo, J. L., Quirce, S., Walusiak, J., .. \& Siracusa, A. (2008). Occupational rhinitis. Allergy: European Journal of Allergy and Clinical Immunology, 63(8), 969-980. https://doi.org/10.1111/j.1398-9995.2008.01801.x

Nagoda, M., Okpapi, J. U., Babashani, M., M, N., \& J.U, O. (2012). Assessment of respiratory symptoms and lung function among textile workers at Kano Textile Mills, Kano, Nigeria. Nigerian journal of clinical practice, 15(4), 373-379. https://doi.org/10.4103/1119-3077.104505

Schilling, R. S. F., Hughes, J. P. W., Dingwall-Fordyce, I., \& Gilson, J. C. (1955). An Epidemiological Study of Byssinosis Among Lancashre Cotton Workers. Brit. J. industr. Med., 12.

Stevens, W. W., \& Grammer, L. C. (2015). Occupational rhinitis: an update. Current allergy and asthma reports, 15(1), 487. https://doi.org/10.1007/s11882-014-0487-8

Sublett, J. W., \& Bernstein, D. I. (2011). Occupational Rhinitis. Immunology and Allergy Clinics of North America, 36(2), 787-796. https://doi.org/10.1016/j.iac.2015.12.009

Zuskin, E., Mustajbegovic, J., Schachter, E. N., Kern, J., Budak, A., \& Godnic-Cvar, J. (1998). Respiratory findings in synthetic textile workers. American Journal of Industrial Medicine, 33(3), 263-273. https://doi.org/10.1002/(SICI)1097-0274(199803)33:3<263::AID-AJIM8>3.0.CO;2-X

\section{Copyrights}

Copyright for this article is retained by the author(s), with first publication rights granted to the journal.

This is an open-access article distributed under the terms and conditions of the Creative Commons Attribution license (http://creativecommons.org/licenses/by/4.0/). 